\title{
Kernos
}

Revue internationale et pluridisciplinaire de religion grecque antique

$30 \mid 2017$

Varia

\section{Quand les dieux voyagent. Cultes et mythes en mouvement dans l'espace méditerranéen antique}

\section{Elie Piette}

\section{OpenEdition}

\section{Journals}

Édition électronique

URL : http://journals.openedition.org/kernos/2524

DOI : $10.4000 /$ kernos.2524

ISSN : 2034-7871

\section{Éditeur}

Centre international d'étude de la religion grecque antique

\section{Édition imprimée}

Date de publication : 1 octobre 2017

Pagination : 334-335

ISSN : 0776-3824

\section{Référence électronique}

Elie Piette, «Quand les dieux voyagent. Cultes et mythes en mouvement dans l'espace méditerranéen antique », Kernos [En ligne], 30 | 2017, mis en ligne le 01 octobre 2017, consulté le 24 septembre 2020. URL : http://journals.openedition.org/kernos/2524 ; DOI : https://doi.org/10.4000/kernos.2524

Ce document a été généré automatiquement le 24 septembre 2020.

Kernos 


\title{
Quand les dieux voyagent. Cultes et mythes en mouvement dans l'espace méditerranéen antique
}

\author{
Elie Piette
}

\section{RÉFÉRENCE}

Corinne BONNET, Laurent BRICAULT, Quand les dieux voyagent. Cultes et mythes en mouvement dans l'espace méditerranéen antique, Genève, Éditions Labor et Fides, 2016. 1 vol. $15 \times 22 \mathrm{~cm}, 314$ p. (Histoires des religions, 4). ISBN : 978-2-8309-1596-9.

1 L'ouvrage est issu d'un séminaire dispensé en 2013 à l'Université de Toulouse Le Mirail (désormais Université Toulouse - Jean Jaurès). Il s'agit du quatrième volume de la collection Histoires des religions, dont l'objectif est la mise à disposition du monde francophone d'études sur l'histoire des religions, dans une démarche comparative. La plupart des chapitres se prêtent effectivement à l'exercice de la comparaison : ainsi, des textes phéniciens et grecs mis en parallèle permettent d'identifier Melqart à Héraclès, ou encore, à Athènes, l'apôtre Paul rencontre des difficultés à expliquer un système religieux qui se pense différemment du sien. Le comparatisme est présent mais le fil conducteur est tout autre. Dans le monde antique, les dieux voyagent, qu'ils soient mésopotamiens, égyptiens, gréco-romains ou qu'il s'agisse du Dieu des juifs et des chrétiens. De la Mésopotamie aux colonnes d'Héraclès, les A. revisitent différents dossiers sous cet angle inédit du déplacement des figures divines. Les raisons d'un tel voyage sont nombreuses: outre l'euocatio romaine et le rôle des dieux dans la colonisation grecque ou phénicienne, des exemples plus spécifiques sont mis en évidence. Un nouvel empereur emmène son dieu à Rome, la présence et l'absence divine structurent le temps et l'espace... Des dieux sont même arrachés à leur peuple lors d'un véritable «Godnapping»! Les déplacements peuvent être historiques mais 
également de l'ordre du mythe : la remuante Ishtar descend aux enfers, un voyage qu'elle regrettera amèrement.

Dans un tel sujet d'analyse, les statues jouent un rôle primordial et ont parfois un destin étonnant, à l'image de celle d'Apollon à Géla : arrachée par les Carthaginois et transmise des années plus tard à la cité-mère de Tyr, la statue est finalement récupérée par Alexandre le Grand lors du siège de la cité phénicienne. Le concept ambigu de statue, distincte du dieu mais investie d'une puissance divine et capable d'agir, est expliqué en détail, tout comme les autres notions essentielles à la compréhension de l'analyse. Car la volonté de vulgarisation est manifeste. Il est parfois nécessaire de patienter, le temps d'excursus de plusieurs pages, avant de saisir le véritable objet du chapitre : ainsi n'est-ce qu'en remontant le temps à la recherche de l'origine de Sarapis que son installation à Délos prend tout son sens. La lecture est allégée par l'absence de notes, mais une orientation bibliographique est proposée à la fin de chaque exposé. Il n'est donc aucunement nécessaire d'être spécialiste pour se plonger dans ce livre. Délos ou Éryx, Hérodote ou Nonnos de Pannopolis, la Bible ou l'Enuma Elish, tous font l'objet d'explications. L'analyse se fonde d'ailleurs essentiellement sur des textes, toujours replacés dans leur contexte. Les A. insistent également sur l'étymologie afin d'éviter tout malentendu ainsi que le danger omniprésent du déterminisme culturel: une "épidémie " divine n'a rien d'une maladie et la notion de relique n'est pas une spécificité chrétienne. La numismatique constitue un autre témoin privilégié : les pièces voyagent tout comme les dieux et fournissent de précieuses indications sur leur représentation.

Conformément à la volonté des A., l'ordre des chapitres n'est ni chronologique, ni téléologique. La lecture s'apparente ainsi à une errance à travers le temps et l'espace. Les titres, parfois énigmatiques («Faut-il se protéger des "épidémies" divines?»; "Pourquoi Ézéchiel mange la Torah?»), renforcent ce sentiment de désordre intentionnel. Au fil des pages cependant, une série d'enjeux s'éclaircissent et facilitent la compréhension à l'aide des réflexions antérieures: la notion de statue, à l'œuvre dans l'épisode d'Artémis à Marseille et d'Apollon à Tyr, fait place à celle du livre, lui aussi symbole de la présence divine. Les deux derniers chapitres, différents en raison de leur référent monothéiste, suscitent le même type de questions et bénéficient des analyses précédentes. Où est Yahvé à la suite de la destruction du temple de Jérusalem ? Comment réussir à implanter la présence du Dieu de Paul dans ce bastion de l'hellénisme qu'est Athènes ? Les acquis des précédents exposés clarifient les modalités et les objectifs de ces déplacements divins. Chaque chapitre peut se lire indépendamment, mais leur addition forme un ensemble cohérent. Attrayant, l'ouvrage emmène le lecteur à travers la Méditerranée, et même au-delà, au côté de ces dieux mobiles. Tout en introduisant l'amateur de religions antiques aux milieux phénicien, anatolien, romain, grec, égyptien, mésopotamien, juif ou chrétien, il fournit, au spécialiste, d'intéressantes analyses sous l'angle original du voyage des dieux. Comme le disent les A., "les voyages forment la jeunesse, dit-on... Ils forment aussi les déesses!». Le seul regret concerne l'absence de conclusion revenant de manière synthétique sur cet ensemble accessible et dépaysant. 


\section{AUTEURS}

\section{ELIE PIETTE}

Université de Liège 